\title{
Incidence, risk, and outcome of reintervention after aortocoronary bypass surgery
}

\author{
KARIN LAIRD-MEETER, RON VANDOMBURG, MARCEL JBM VANDEN BRAND, \\ JACOBUS LUBSEN, EGBERT BOS, PAUL G HUGENHOLTZ \\ From the Thorax Center, University Hospital Dijkzigt, Erasmus University Rotterdam, The Netherlands
}

SUMMARY Reintervention was required in $123(12 \%)$ individuals during a follow up (mean 7.5 years, range 5-14.5) of 1041 patients with consecutive, isolated, first aortocoronary bypass operations. In 89 patients the intervention was a repeat bypass operation, in 24 it was angioplasty, and 10 had both. Procedure related mortality was significantly higher at reintervention (5.6\%) than at the primary operation $(1.2 \%)$. Survival probability after a single bypass procedure was $90 \%$ at six years and $82(3) \%$ at nine years. Corresponding figures six and nine years after reintervention were $89(6) \%$ and $87(7) \%$ respectively. Stepwise multivariate analysis showed that survival was significantly correlated with left ventricular function (rate ratio 1.82) and with extent of vascular disease (rate ratio 1.80) but not with reintervention (rate ratio 1.45). Symptomatic improvement occurred in $89 \%$ of the survivors with or without reintervention.

Repeat procedures are often necessary after coronary artery bypass grafting but they appear to provide appreciable relief of symptoms without reducing any long term improvement in survival brought about by the original operation.

Coronary artery bypass grafting has been used successfully to treat angina pectoris since $1968 .^{1}$ It is now clear that it is not a definitive treatment. Most patients experience an improvement in symptoms but this relief decreases with time. ${ }^{2-4}$ Both Campeau $e t$ al and Lytle et al reported an accelerated loss of graft patency after five years or more. ${ }^{56}$ Moreover, atherosclerosis is a progressive disease. As a result, reoperations after coronary artery bypass grafting are increasingly performed ${ }^{7-9}$ and angioplasty has been introduced to improve myocardial blood flow either by dilatation of a stenosed bypass graft or by dilatation of an unbypassed narrowed native artery. ${ }^{1011}$

To assess the frequency of re-revascularisation achieved by re-grafting or angioplasty, we studied a group of consecutive patients who had isolated coronary artery bypass grafting before July 1980 . We looked especially at symptomatic improvement after both these procedures, the timing, the procedure

Requests for reprints to Dr Karin Laird-Meeter, Thorax Center, University Hospital Dijkzigt, Dr Molewaterplein 40, 3015 GD Rotterdam, The Netherlands.

Accepted for publication 18 December 1986 related risk(s), and the probability of long term survival with and without reintervention.

\section{Patients and methods}

PATIENT SELECTION AND CHARACTERISTICS

We studied the 1041 patients who had undergone isolated aortocoronary bypass surgery at our hospital between 1971 and July 1980. The indication for the original operation was angina pectoris unrelieved by the pharmacological treatment that was considered optimal at that time. Table 1 shows the clinical characteristics of these patients. Follow up data on this series of patients have been reported elsewhere. ${ }^{1213}$ All reinterventions performed in this group of patients up to July 1985 are included. Before 1982 a reintervention meant a coronary artery bypass re-grafting, whereas after 1982 an angioplasty procedure was performed in selected cases. If more than one reintervention had been performed, the first was used as the data collection point.

CATHETERISATION DATA

A selective coronary angiogram was obtained in all patients before a procedure. A vessel was considered 
Table 1 Clinical characteristics of patients at primary operation $(n=1041)$ and at the primary and repeat procedure in those who had reintervention $(n=123)$

\begin{tabular}{|c|c|c|c|c|c|c|}
\hline \multirow[b]{2}{*}{ Data } & & & \multicolumn{4}{|c|}{ Patients with reintervention } \\
\hline & \multicolumn{2}{|c|}{ Entire cohort at primary operation } & \multicolumn{2}{|c|}{ At 1st operation $\star$} & \multicolumn{2}{|c|}{ At reintervention } \\
\hline \multirow{5}{*}{$\begin{array}{l}\text { Men } \\
\text { Women } \\
\text { Age: } \\
\leqslant 50 \\
51-60 \\
>60 \\
\text { Mean } \\
\text { Diseased: } \\
\text { 1 vessel } \\
2 \text { vessels } \\
3 \text { vessels } \\
\text { Left main } \\
\text { Ejection fraction: } \\
\geqslant 0 \cdot 55 \\
0.31-0.55 \\
\leqslant 0.30 \\
\text { Unknown } \\
\text { Validity: } \\
\text { NYHA class I } \\
\end{array}$} & $\begin{array}{l}915 \\
126\end{array}$ & $\begin{array}{l}(88 \%) \\
(12 \%)\end{array}$ & $\begin{array}{r}114 \\
9\end{array}$ & $\begin{array}{c}(93 \%) \\
(7 \%)\end{array}$ & $\begin{array}{r}114 \\
9\end{array}$ & $\begin{array}{c}(93 \%) \\
(7 \%)\end{array}$ \\
\hline & $\begin{array}{l}360 \\
489 \\
192 \\
53 \cdot 4 \dagger\end{array}$ & $\begin{array}{l}(35 \%) \\
(47 \%) \\
(18 \%)\end{array}$ & $\begin{array}{l}63 \\
53 \\
7 \\
49 \cdot 7 \dagger\end{array}$ & $\begin{array}{c}(51 \%) \\
(43 \%) \\
(6 \%)\end{array}$ & $\begin{array}{l}33 \\
66 \\
24 \\
54 \cdot 2\end{array}$ & $\begin{array}{l}(27 \%) \\
(54 \%) \\
(19 \%)\end{array}$ \\
\hline & $\begin{array}{r}192 \\
320 \\
444 \\
85\end{array}$ & $\begin{array}{c}(19 \%) \\
(31 \%) \\
(42 \%) \\
(8 \%)\end{array}$ & $\begin{array}{l}25 \\
41 \\
47 \S \\
10 \S\end{array}$ & $\begin{array}{c}(20 \%) \\
(34 \%) \\
(38 \%) \\
(8 \%)\end{array}$ & $\begin{array}{l}11 \\
19 \\
81 \S \\
12 \S\end{array}$ & $\begin{array}{c}(9 \%) \\
(15 \%) \\
(66 \%) \\
(10 \%)\end{array}$ \\
\hline & $\begin{array}{c}600 \ddagger \\
248 \ddagger \\
27 \\
166\end{array}$ & $\begin{array}{l}(57 \%) \\
(24 \%) \\
(3 \%) \\
(16 \%)\end{array}$ & $\begin{array}{c}84 \ddagger \\
16 \ddagger \\
3 \\
20\end{array}$ & $\begin{array}{l}(68 \%) \\
(13 \%) \\
(3 \%) \\
(16 \%)\end{array}$ & $\begin{array}{r}78 \\
31 \\
3 \\
11\end{array}$ & $\begin{array}{c}(63 \%) \\
(25 \%) \\
(3 \%) \\
(9 \%)\end{array}$ \\
\hline & $\begin{array}{l}0 \\
\text { Subdi }\end{array}$ & $(0 \%)$ & $\begin{array}{l}- \\
46 \\
66 \\
11\end{array}$ & $\begin{array}{c}(0 \%) \\
(37 \%) \\
(54 \%) \\
(9 \%)\end{array}$ & $\begin{array}{r}- \\
69 \\
53\end{array}$ & $\begin{array}{c}(0 \%) \\
(1 \% \%) \\
(56 \%) \\
(43 \%)\end{array}$ \\
\hline
\end{tabular}

*At primary operation of group with subsequent reintervention; $\nmid p<0.001$, entire cohort $v s$ reintervention group; $\ddagger$ p $<0.005$, entire cohort $v s$ reintervention group; $\$ p<0.001$, reintervention group at primary operation $v s$ at reintervention.

to be diseased when a luminal narrowing of $>50 \%$ was seen in more than one projection. Coronary disease was classified as one, two, three, or left main vessel disease. At repeat catheterisation the bypass graft was injected selectively where possible. If the bypass graft could not be opacified and if the graft was found to be closed at operation or if the graft could be opacified but showed a narrowing of $>90 \%$ the graft was regarded as a failure. We diagnosed progression of atherosclerosis if at a later catheterisation a major artery showed an increase in luminal narrowing from a previously normal or $<50 \%$ narrowed lumen to narrowing of $\geqslant 50 \%$ or from $\geqslant 50 \%$ narrowing to a total or subtotal occlusion.

If a severely narrowed major vessel could not be bypassed at operation revascularisation was regarded as inadequate. A surgical procedure was considered to have been faulty if the bypass graft was either incorrectly placed on the intended artery or was placed on the wrong artery.

Left ventricular angiography was performed in all patients. If the angiogram was technically satisfactory an ejection fraction was calculated. Ejection fractions of $\geqslant 0.55$ were considered to be normal; those of $\leqslant 0.30$ were called poor and those that were $>0.30$ but $<0.55$ were described as moderately decreased.

\section{ANGIOPLASTY}

In 1982 angioplasty procedures were first used at our hospital on patients with coronary artery bypass grafts. The technique of Grüntzig et $a l^{14}$ was used with a steerable balloon catheter inserted via the femoral route. Of the patients in this study group 14 underwent dilatation of a narrowed or occluded bypass graft, 19 had dilatation of one or more native coronary arteries, and one had dilatation of a bypass graft and a native vessel in the same session. Indications for the procedure were: symptoms of myocardial ischaemia in a patient in whom angiography showed that dilatation was feasible or a distal coronary vascular bed with poor run off which precluded surgical treatment (six cases). In the latter case only the ischaemia related vessel was dilated as an emergency measure ${ }^{15}$ because no alternative method of treatment could be used.

A dilatation was regarded as successful when it resulted in clinical relief of the symptoms of ischaemia, when the residual stenosis was $<50 \%$ of the luminal diameter and the mean pressure gradient across the stenosis, normalised for aortic pressure, had decreased to 0.30 of the original. The procedure was judged to have been successful in $25(74 \%)$ patients. In one $(3 \%)$ patient an emergency operation was necessary; in five $(15 \%)$ others coronary artery bypass grafting followed one week to seven months later.

\section{SURGICAL TECHNIQUE}

All patients in the study were originally operated on by the same team. In 1977 sequential grafting was introduced ${ }^{16}$ and in 1983 topical cardiac cooling was replaced by cold cardioplegic arrest with St 
Table 2 Mean number of distal anastomoses per patient made at the primary operation in the groups without and with subsequent intervention

\begin{tabular}{|c|c|c|c|c|}
\hline \multirow[b]{2}{*}{ Vessels diseased at primary operation } & \multicolumn{2}{|l|}{ No reintervention } & \multicolumn{2}{|l|}{ Reintervention later } \\
\hline & Number of patients & Anastomoses per patient & Number of patients & Anastomoses per patient \\
\hline $\begin{array}{l}1 \text { vessel } \\
2 \text { vessels } \\
3 \text { vessels } \\
\text { Left main } \\
\text { Total }\end{array}$ & $\begin{array}{r}167 \\
279 \\
397 \\
75 \\
918\end{array}$ & $\begin{array}{l}1 \cdot 4 \\
2 \cdot 3 \\
3 \cdot 4 \\
3 \cdot 4 \\
2 \cdot 6\end{array}$ & $\begin{array}{r}25 \\
41 \\
47 \\
10 \\
123\end{array}$ & $\begin{array}{l}1 \cdot 4 \\
2 \cdot 3 \\
3 \cdot 3 \\
3 \cdot 0 \\
2 \cdot 5\end{array}$ \\
\hline
\end{tabular}

Thomas's Hospital solution for myocardial preservation. ${ }^{17}$

In all instances complete revascularisation was attempted. At the original surgical procedure a mean of 2.6 distal anastomoses were made (range 1-7). At the repeat operation vascularisation was improved in all but two patients. One of these was given an aortic valve prosthesis and the other underwent aneurysmectomy and mitral valve replacement.

\section{FOLLOW UP}

Follow up data were determined through the civil registry: $99 \%$ of the 1041 patients could be traced. Deaths from all causes were included in the analysis. A complete follow up of the group with a reintervention was possible. After a reintervention the treating physician or the principal investigator assessed the occurrence of symptoms in each patient. Angina pectoris was regarded as present after a procedure if the subject experienced chest pain with the same characteristics as before the operation. The New York Heart Association classification was used.

\section{STATISTICAL ANALYSIS}

Where appropriate the $\chi^{2}$ contingency test was used. The probability of survival was calculated by the Kaplan and Meier method. ${ }^{18}$ To determine whether a reintervention constituted a separate risk in long term survival, data were analysed by a stepwise nonlinear algorithm of the Cox proportional hazards model. ${ }^{1920}$ For those patients who did not have a second procedure, we entered the appropriate data collected at the time of the original operation. Otherwise, the data were collected at the time of reintervention.

\section{Results}

Within follow up (minimum five years, mean 7.5 years) $123(12 \%)$ patients of the study population had a repeat intervention. The symptoms and vascular lesions shown by these patients at the original coronary artery bypass grafting were similar to those of the 918 who did not have a reintervention (table 1).

The patients with a reintervention were younger at the initial operation ( 49.7 years vs 53.4 years $(p<0.001))$ and their left ventricular function, as expressed by ejection fraction, was better (table 1 ). The ejection fraction was normal in $84(68 \%)$ of the 123 patients who needed a reintervention; it was moderately decreased in $16(13 \%)$. In the 918 patients who did not have a reintervention at a later date $56 \%$ had a normal ejection fraction and $25 \%$ had a moderately decreased one $(p=0.002)$.

The number of grafts implanted did not differ greatly in the two groups. Table 2 shows that a mean of 2.5 distal anastomoses was made in the reintervention group compared with 2.6 in the group without subsequent reintervention.

No consistent data were available on established risk factors such as hyperlipidaemia and high blood pressure. Patients with these risk factors were treated appropriately.

\section{CHANGES IN THE REINTERVENTION GROUP}

Table 1 shows the characteristics of the 123 patients who needed a reintervention. There was a striking change in symptoms. Before the primary operation $46(37 \%)$ patients were in class II; at the time of the reintervention only one patient was in this class. The number of patients with angina pectoris at rest despite maximal pharmacological treatment (class IV) had increased from $11(9 \%)$ to $53(43 \%)$.

Table 1 also shows that at primary operation slightly more than half the patients had one or two vessel disease $(66(54 \%)$ vs $57(46 \%)$ with three vessel or left main disease). At reintervention this distribution had changed significantly to $30(24 \%)$ and $93(76 \%)$ respectively $(\mathrm{p}<0.001)$.

\section{INTERVAL BETWEEN PROCEDURES}

The interval between the initial coronary artery bypass grafting and reintervention ranged from 1.5 months to 12.5 years (mean 4.5 years). In the first postoperative year 23 patients $(2.3 \%$ of the first year 
Table 3 Anatomical lesion at reintervention with time of occurrence of angina pectoris in months after the primary operation

.

survivors) underwent a reoperation. Figure 1 shows the cumulative number of patients with a reintervention. The number of patients needing a reintervention (11 per year) remained constant up to the tenth postoperative year. Angioplasty was gradually introduced several years after the intake of patients in the study group had stopped.

\section{ANATOMICAL LESION AT REINTERVENTION}

At reintervention the predominant finding was graft failure in $98(80 \%)$ of the 123 patients. There was pure graft failure without changes in the native coronary vessels in $32(26 \%)$ patients. In $24(20 \%)$ graft failure was noted with progression of vascular lesions in the grafted artery and in $42(34 \%)$ we found graft failure and progression of atherosclerosis in a non-grafted artery with or without progression in the grafted vessel (table 3). All intended grafts were functioning correctly in only 17 $(14 \%)$ of the 123 patients. Fifteen of these 17 patients had progression of lesions in the non-

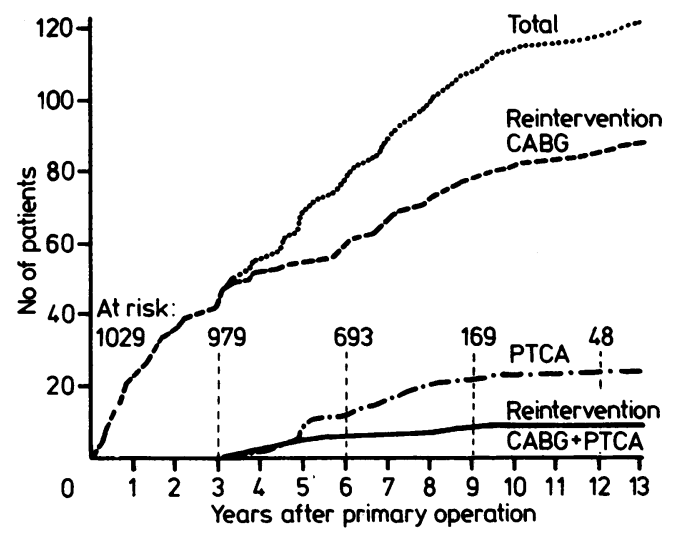

Fig 1 Cumulative number of patients with a reintervention (re-grafting, angioplasty, or both) versus interval since the primary bypass operation. The increase is constant from the second to the 10th postoperative year despite the decreasing number of patients at risk. PTCA, percutaneous transluminal coronary angioplasty. $C A B G$, repeat coronary artery bypass grafting. grafted arteries and in two an aortic valve stenosis had developed with mean gradients across the valve of 75 and $90 \mathrm{~mm} \mathrm{Hg}$. Three other patients with aortic valve disease also had failing grafts at reoperation.

The failure rate of the grafts at a mean of $4 \cdot 2$ years after the initial operation in the patients needing a reintervention was $72 \%(226 / 312)$; the usual overall failure rate three years after operation at that time was $24 \%{ }^{21}$

\section{PERIOPERATIVE MORTALITY}

The 28 day operative mortality after the primary coronary artery bypass grafting procedure was $1.2 \%$ $(12 / 1041)$. After a reintervention $6.5 \%(8 / 123)$ of the patients died. Some patients needed a second angioplasty or a surgical intervention after angioplasty. In total 142 procedures were performed (table 4), with a procedure related mortality of $5 \cdot 6 \%(8 / 142)$. Mortality after reintervention was significantly higher than after the first coronary artery bypass grafting $(p<0.005)$. Most cases of perioperative death were caused by an acute myocardial infarction during, shortly before, or shortly after the procedure.

LONG TERM SURVIVAL

Figure 2 shows the probability of survival for the

Table 4 Mortality related to reoperation and angioplasty in 123 patients with previous bypass surgery

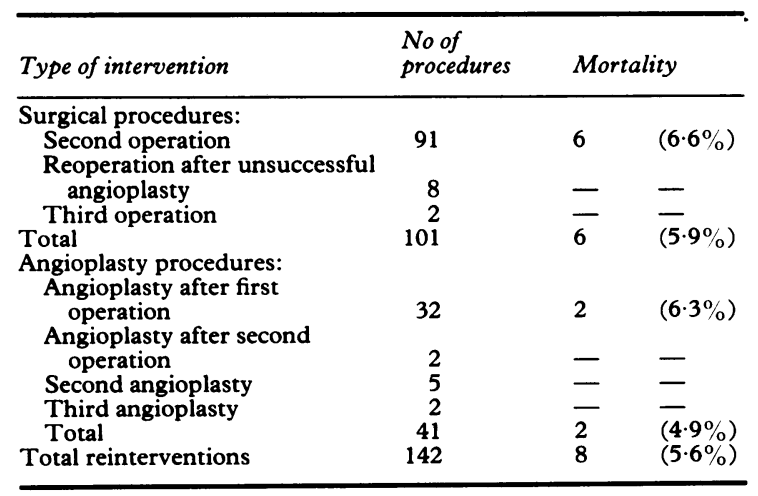




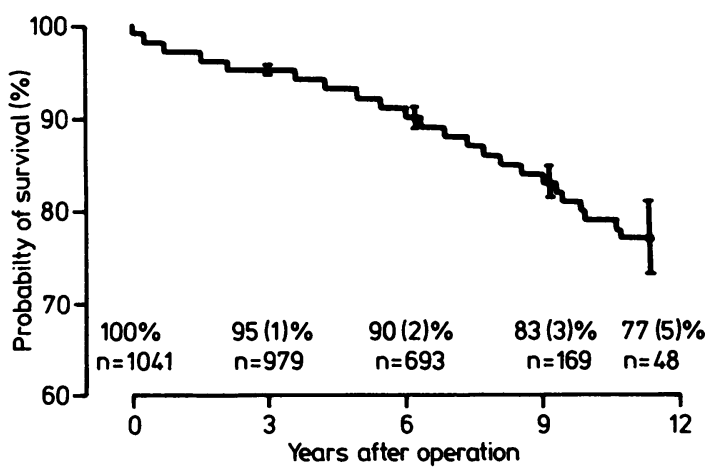

Fig 2 Probability of survival in the total group plotted against time after surgery. The number of patients alive at the end of each year is shown. The vertical bars are the $95 \%$ confidence interval. entire group of 1041 patients after the primary coronary artery bypass grafting. Five years after operation survival was $92 \%$, at six years it was $90(2) \%$, and at nine years it was $83(3) \%$. In those who had a reintervention the three year probability of survival was $98(2) \%$, at six years it was $96(3) \%$, and at nine years it was $91(6) \%$. After exclusion of the perioperative mortality associated with the primary operation the probability of survival in the patients who did not have a reintervention was slightly lower than that in the patients who did $(96(2) \%, 91(2) \%$, and $83(3) \%$ at 3,6 , and 9 years respectively). Figure 4 shows the survival curve of the same patients starting at either the initial bypass operation or the first reintervention. The intervention related mortality is included. Thus the long term survival rate after a first revascularisation may be compared with that

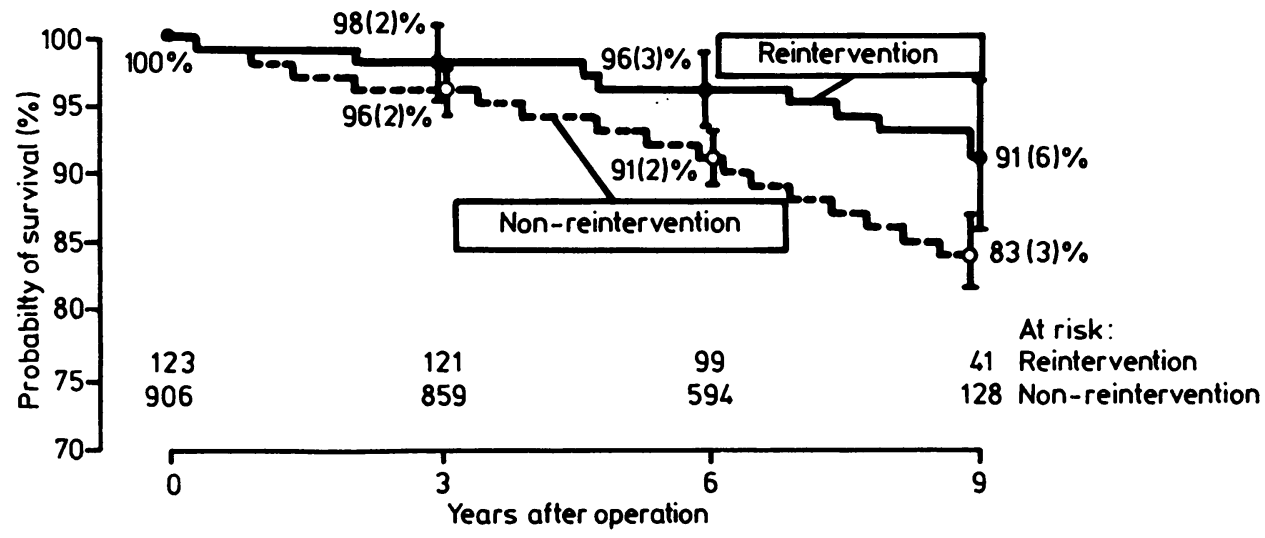

Fig 3 Probability of survival for patients with and without a subsequent reintervention plotted against time after the initial operation. Operative mortality at original surgery is excluded. The number of patients alive at the end of each year is shown. The vertical bars are the $95 \%$ confidence interval.

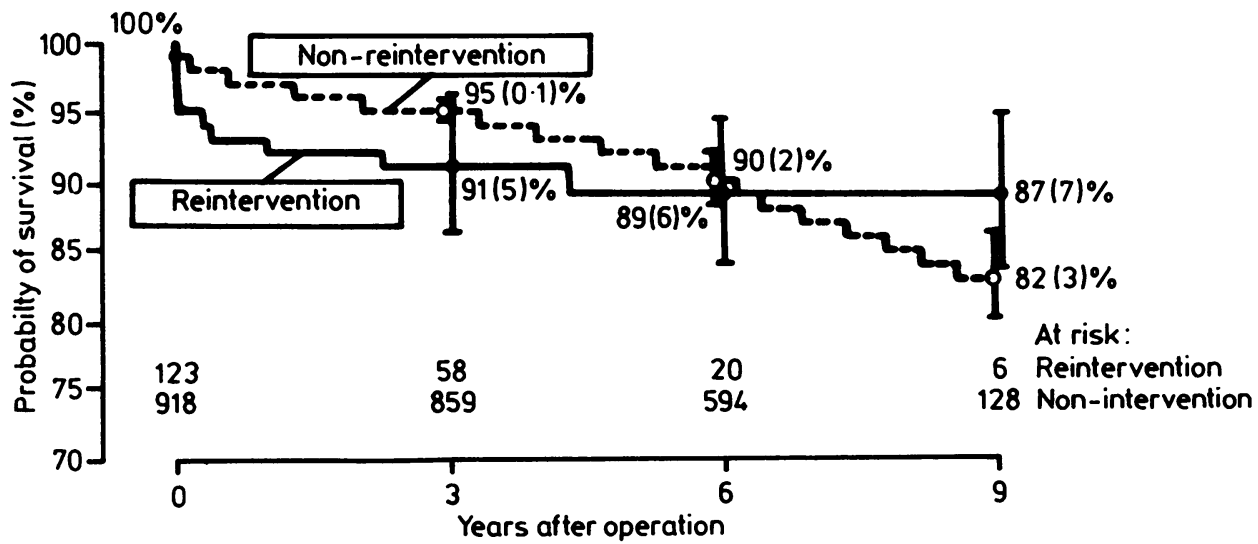

Fig 4 Probability of survival after a first bypass operation and after a second procedure, plotted against time after either intervention. The number of patients in each group alive at the end of each year is shown. The vertical bars are the $95 \%$ confidence interval. 
Table 5 Rate ratio from Cox's regression analysis of survival

\begin{tabular}{|c|c|c|}
\hline Factor & Rate ratio & p value \\
\hline \multicolumn{3}{|l|}{$\begin{array}{l}\text { Age at operation: } \\
\text { Continuous variable }\end{array}$} \\
\hline \multirow{2}{*}{$\begin{array}{l}\text { Sex: } \\
\text { Men } \\
\text { Women vs men }\end{array}$} & & \\
\hline & $\begin{array}{l}\text { Reference category } \\
1 \cdot 12\end{array}$ & $\overline{N S}$ \\
\hline \multirow{2}{*}{$\begin{array}{l}\text { Vascular disease: } \\
1 \text { vessel disease } \\
2 \text {, 3, and LM vs } 1 \text { vessel disease } \\
3 \text { and LM vs } 1 \text { vessel disease }\end{array}$} & & \\
\hline & $\begin{array}{l}\text { Reference category } \\
1 \cdot 18 \\
1 \cdot 80\end{array}$ & $\begin{array}{l}\overline{N S} \\
0.01\end{array}$ \\
\hline \multirow{4}{*}{$\begin{array}{l}\text { Ejection fraction: } \\
\text { Normal } \\
\text { Depressed vs normal } \\
\text { Non-reintervention group } \\
\text { Re-intervention vs } \\
\text { non-reintervention }\end{array}$} & & \\
\hline & $\begin{array}{l}\text { Reference category } \\
1.82\end{array}$ & $\overline{0.0007}$ \\
\hline & Reference category & - \\
\hline & 1.45 & NS \\
\hline
\end{tabular}

LM, left main stem coronary artery disease.

after a re-revascularisation. The initially high procedure related mortality in the reintervention group gave a probability of survival to three years of $91(5) \%$; the corresponding result after a first grafting procedure was $95 \%$ (this figure takes account of the perioperative mortality). The probability of survival to six years was similar in the two groups: $89(6) \%$ and $90(2) \%$. The likelihood of survival to nine years in the reintervention group was $87(7) \%$.

\section{RELATIVE RISK OF REINTERVENTION}

To discover whether reintervention poses a risk that is independent of other recognised risk factors such as preoperative vascular disease and reduced ejection fraction, we performed a stepwise multivariate analysis. For the reintervention group we entered data collected at the time of the procedure. For patients without a reintervention we used the data collected at the primary operation. The reintervention was entered as a separate item. The results of the analysis are expressed as rate ratiosthat is the death rate (number of events per unit of person-time of follow up) in a particular category divided by the death rate in a reference category, given that other characteristics entered in the survival model are equal. Table 5 shows the rate ratio point estimates. The only statistically significant predictors of long term survival were the extent of vascular disease and the ejection fraction. The reintervention in itself did not carry an additional risk, all other factors being equal (the rate ratio of reintervention versus first revascularisation was $1 \cdot 45, \mathrm{NS})$.

SYMPTOMS AT FOLLOW UP

Just before reintervention $122(99 \%)$ patients were either in class III or IV of the New York Heart Association classification. At follow up, a mean of
2.9 years after the reintervention (range 0.1-12.6 years) none of the 107 survivors were in class IV, 14. $(13 \%)$ were in class III, and $45(42 \%)$ were in class $\vec{F}$ II. Overall, $49 \%$ (52 of the 107 survivors) still had $\stackrel{5}{\circ}$ symptoms of angina, but $89 \%$ felt definitely improved. Three years after operation $42 \%$ of the $\bar{c}$. patients with one grafting procedure had anginal $\vec{\nabla}$ complaints; in $15 \%$ the symptoms were mild and did not limit daily activity. Eighty nine per cent of the $\tilde{\omega}$ reintervention group reported that they felt better $\vec{O}$ after the procedure. Thus the frequency of angina pectoris was not significantly different in the group $\omega$ that had a reintervention and those that had only a primary operation.

\section{Discussion}

It was reassuring to find that the probability of survival after a reintervention was not significantly $\rightarrow$ different from that after the first coronary artery bypass grafting procedure. At first glance this seems to be inconsistent with the higher procedure related mortality at repeat intervention: $5.6 \%$ vs $1.2 \%$ for the first coronary artery bypass grafting. Loop et al from the Cleveland Clinic reported a higher perioperative mortality rate at reoperation too. ${ }^{8}$ They reported that operative mortality decreased from $4.8 \%$ in the early years of the technique to $2 \%$ in 1981 and 1982; this is still higher than the usual mortality rate for a first coronary artery bypass grafting procedure $(<1 \%)$. Forster et al compared operative mortality for repeat and initial coronary artery bypass grafting in the Coronary Artery Surgery Study registry. They reported that the risk was increased from $3.1 \%$ to $5.3 \%$ at reoperation. ${ }^{22}$ Yet we and other investigators found that survival after reoperation compared well with that after first coronary artery bypass grafting. In Loop et al's series, overall five year survival was $89 \%$ in their first 750 patients. ${ }^{8}$ Reul et al reported a cumulative seven year survival of $82 \%$ in 168 patients who had $\frac{7}{0}$ a reoperation ${ }^{23}$; this is very similar to the survival rate of $84 \%$ at seven years that they reported for $\mathrm{N}$ their entire revascularisation series of 13049 cases.

We found a high survival rate in patients who required a reintervention in the course of their disease. Six years after a bypass procedure $96(3) \%$ of patients who had a reintervention were alive and $91(2) \%$ of those without a repeat procedure were $\stackrel{D}{\sim}$ alive.

Selection bias may well be responsible for this result. Patients who later required reintervention $\stackrel{\mathbb{D}}{D}$ were younger at the initial surgery and had better $\mathbb{D}$ left ventricular function at that time; however, $\frac{O}{\sigma}$ symptoms and preoperative vascular disease were similar in the two groups. Selection bias (at entry 
patients who later had reoperation had different characteristics from those who did not) was found in the Coronary Artery Surgery Study too. ${ }^{22}$ Moreover, to be selected for a repeat revascularisation patients must reach the hospital alive without other important disease.

Despite the higher initial mortality associated with the repeat procedure, long term survival was the same after a repeat revascularisation procedure as after initial coronary artery bypass grafting. Statistical testing in which the extent of vascular disease and left ventricular function were controlled for showed that intervention did not have an independent adverse influence on survival.

\section{REASON FOR REINTERVENTION}

Several factors may account for coronary artery bypass grafting being less successful than expected: faulty operative technique, early thrombotic obstruction of the grafts, ${ }^{2425}$ failure of the graft caused by fibrous intimal proliferation (generally occurring during the first postoperative year), ${ }^{25}$ graft atherosclerosis several years after coronary artery bypass grafting, ${ }^{26}$ and progression of the atherosclerotic disease in the native coronary vasculature. ${ }^{5}$ All these factors were found in our series. One patient also had mitral valve insufficiency and five had aortic valve stenosis. These are unusual reasons for reintervention, but they were found during a follow up of consecutive patients.

Early graft failure with persistent angina was seen in $18 \%(22 / 123)$ of the patients who had reintervention. There was recurrence of pain after an angina free interval of up to three years caused by pure graft failure in $8 \%(10 / 123)$. Progression of obstruction but with patent grafts was seen in patients who had symptoms more than a year after operation. Late recurrence of symptoms was related to progression of atherosclerosis in native arteries as well as in grafts. Hence, the timing of the occurrence of symptoms did not indicate their underlying cause.

\section{FREQUENCY OF REINTERVENTION}

Soon after coronary artery bypass grafting became a routine operation it was realised that some patients would require reoperation, but what proportion was not known. Loop et al assume that $7 \%$ of today's patients will undergo a reoperation in the next 10 years. ${ }^{8}$ Lawrie et al found a $9 \%$ reoperation rate during 10 years of follow up. ${ }^{27}$ Others have reported reoperation rates as high as $33 \%$ in patients operated on between 1970 and 1975; this rate decreased, however, with more experience with these operations. ${ }^{28}$ The reintervention rate of $12 \%$ in our study, during a mean follow up of 7.5 years, is disturbingly high. This may, in part, be related to the effect of the learning curve. Undoubtedly, fewer grafts were implanted in the early 1970s than at present. Some workers argue that the greater the number of grafts that are initially implanted in a patient the less likely is progressive atherosclerosis to develop in previously ungrafted arteries and to become an indication for reoperation. ${ }^{829}$ In our study a similar number of grafts were inserted at the initial coronary artery bypass grafting in patients with and without a later intervention.

The high reintervention rate in our population might also have been the result of increased progression of atherosclerosis in the grafts and native arteries. The overall survival of the total group of 1041 patients, which compares favourably with other series, however, argues against this. Five year survival in our study $(92(2) \%)$ resembles five year survival after surgery reported by Myers $e t$ al in the Coronary Artery Surgery Study, ${ }^{30}$ by Cosgrove et al at the Cleveland Clinic, ${ }^{31}$ and by Varnauskas in the European Coronary Surgery Group ${ }^{32}(90 \%$, $93.2 \%$, and $92.4 \%$ respectively). The 10 year survival of $79.3 \%$ in the Cleveland Clinic series ${ }^{31}$ accords with our result $(79(4) \%)$.

Lastly, the high reintervention rate might be inherent in the local referral process. The decision to use invasive treatment was not taken lightlypatients had severe symptoms before reintervention. Patients with unstable angina pectoris were referred by the cardiology service, whereas those with stable symptoms were referred directly to the surgical service. All patients entered the same register. This reintervention rate may more closely reflect the real position than a study based on referral to a distant centre for purely elective procedures. Moreover, our study included angioplasty procedures as reinterventions. The cumulative graph of patients requiring a reintervention over time (fig 1 ) shows a steady rise in the number of patients needing a reintervention, despite the decrease in the number of patients at risk. The cause for the reintervention is clearly a continuing vascular disorder, which progresses with time. This increase may correspond with the accelerated loss of graft patency years after coronary artery bypass grafting as described by Campeau et al. ${ }^{26}$

\section{ANGIOPLASTY VERSUS CORONARY ARTERY} BYPASS GRAFTING

The treatment results of coronary artery bypass grafting and angioplasty cannot be compared because only 34 patients had angioplasty. Twenty eight patients had the conventional indication for angioplasty-a localised lesion in a vessel without many collaterals - and in six the lesion was unsuitable for surgical intervention. It was the treatment 
of last resort for unstable angina unresponsive to intensive pharmacological treatment. In these patients the ischaemia related vessel was dilated as described by de Feyter et al. ${ }^{15}$ Hartzler et al reported a success rate of $92 \%$ and a mortality of $5.6 \%$ in a series of 500 patients with multivessel disease $^{33}$; our success rate was lower $(74 \%)$, as was our mortality rate of $4.9 \%$. Nevertheless, angioplasty is an alternative to coronary artery bypass grafting, both for dilatation of native vessels and grafted vessels. ${ }^{1011}$

\section{SUBJECTIVE CONDITION AT FOLLOW UP}

Complete relief of anginal complaints is reportedly achieved less often after a reoperation than after a first coronary artery bypass grafting. ${ }^{813}$ In the present study this was not the case. We found that $49 \%$ of the survivors had anginal symptoms after their reintervention; this resembles the results in patients three years after a single operation $(42 \%)$. In a previous study of 53 patients with reoperations followed up for a mean of 3.5 years after the original operation we found that $68 \%$ of patients had angina. ${ }^{13}$ It is possible that the recent improvement has been brought about by increased experience.

Loop et al found that $48 \%$ of patients had angina after reoperation whereas after a single operation only $25 \%$ had symptoms. ${ }^{8}$ This last low percentage might be caused by the use of a different method as Campeau $e t a l^{3}$ found a recurrence rate of anginal complaints after a single operation that was similar to ours.

\section{LIMITATIONS OF THE STUDY}

Ours is not a prospective study nor did we perform serial cardiac catheterisation. Therefore, we do not know when atherosclerosis started in the bypass grafts. Moreover, data on risk factors, such as lipid spectrum and level of blood pressure were not recorded consistently at the start of the study. Thus it was not possible to correlate risk factors with the likelihood of subsequent reintervention.

It is not uncommon for patients with coronary bypass grafts to require a reintervention because of severe angina. We found, however, that with the current techniques the long term prognosis is good. When the extent of vascular disease and left ventricular function are taken into consideration the survival probability is as good as after a first bypass procedure, and there is a considerable improvement in symptoms after the procedure.

\section{References}

1 National Institutes of Health Consensus Development Statement. Coronary-artery bypass surgery: scien- tific and clinical aspects. $N$ Engl $J$ Med 1981; 304:680-4.

2 Rahimtoola S. Coronary bypass surgery for chronic angina 1981. A perspective. Circulation 1982;65: 225-41.

3 Campeau L, Lespérance J, Hermann J, Corbara F, Grondin CM, Bourassa MG. Loss of improvement of angina between one and seven years after coronary bypass surgery. Circulation 1979;60(suppl I)I:1-5.

4 Cameron A, Kemp HG, Shimomura S, et al. Aorto है coronary bypass surgery. A 7-year follow-up. Circulation 1979;60(suppl I) I:9-13.

5 Campeau L, Enjalbert M, Lespérance J, et al. The relation of risk factors to the development of atherosclerosis in saphenous-vein bypass grafts and the progression of disease in the native circulation. $N$ Engl J Med 1984;311:1329-32.

6 Lytle BW, Loop FD, Cosgrove DM, Ratcliff NB, Easley K, Taylor PC. Long-term (5-12 years) serial studies of internal mammary artery and saphenous vein coronary bypass grafts. $J$ Thorac Cardiovasc Surg 1985;89:248-58.

7 Schaff HV, Orszulak TA, Gersh BJ, et al. The morbidity and mortality of reoperation for coronary artery disease and analysis of late results with use of actuarial estimate of event free interval. $J$ Thorac Cardiovasc Surg 1983;85:508-15.

8 Loop FD, Lytle BW, Gill CC, Golding LAR, Cosgrove DM, Taylor PC. Trends in selection and results of coronary artery reoperations. Ann Thorac Surg 1983;36:380-8.

9 Foster ED. Reoperation for coronary artery disease. Circulation 1985;72(suppl V)V:59-64.

10 Jones EL, Douglas JS, Grüntzig AR, et al. Percutaneous saphenous vein angioplasty to avoid re-operative bypass surgery. Ann Thorac Surg 1983;36:389-95.

11 Block PC, Cowley MJ, Kaltenbach M, Kent KM, Simpson J. Percutaneous angioplasty of stenoses of bypass grafts or of bypass graft anastomotic sites. $\mathrm{Am}$ $J$ Cardiol 1984;53:666-8.

12 Laird-Meeter K, Penn OCKM, Haalebos MMP, et al. Survival in 1041 patients with consecutive aorto coronary bypass operations. Eur Heart J 1984;5: 35-42.

13 Laird-Meeter K, van den Brand MJBM, Serruys PW, D et al. Reoperation after aortocoronary bypass procedure. Results in 53 patients in a group of 1041 with $\mathrm{N}$ consecutive first operations. Br Heart J 1983;50: C 157-62.

14 Grüntzig AR, Senning A, Siegenthaler WE. Non- N operative dilatation of coronary artery stenosis: percutaneous transluminal coronary angioplasty. $N \mathrm{Engl}$ J Med 1979;301:61-7.

15 de Feyter PJ, Serruys PW, van den Brand MJBM, et al. Emergency coronary angioplasty in refractory : unstable angina. $N$ Engl J Med 1985;313:342-6.

16 Brower RW, van Eijk KF, Bos E. Sequential versus conventional coronary artery bypass graft surgery in matched patient groups. J Thorac Cardiovasc Surg 1981;29:158-62.

17 Hearse DJ, Stewart DA, Braimbridge MV. Cellular protection during myocardial ischemia: the develop- 
ment and characterisation of a procedure for the induction of reversible ischemic arrest. Circulation 1976;54:193-202.

18 Kaplan EL, Meier P. Nonparametric estimation from incomplete observation. J Am Stat Assoc 1958;53: 457-81.

19 Cox DR. Regression models and lifetables. $J \boldsymbol{R}$ Soc Med (London) 1972;34:187-220.

20 Hopkins A. BMDP statistical software. Dixon WJ, ed. (1983 printing with addition.) Berkeley: University of California Press, 1983:290-334.

21 Brower RW, Laird-Meeter K, Serruys PW, Meester GT, Hugenholtz PG. Long term follow-up after coronary artery bypass graft surgery. Progression and regression of disease in native coronary circulation and bypass grafts. Br Heart $J$ 1983;50:42-7.

22 Forster ED, Fisher LD, Kaiser GC, Myers WO. Principal investigators of CASS and their associates. Comparison of operative mortality and morbidity for initial and repeat coronary artery grafting: the coronary artery study (CASS) registry experience. Ann Thorac Surg 1984;38:563-70.

23 Reul GJ, Cooley DA, Coelho A, Chapa L, Eterovic I. Reoperation for recurrent coronary artery disease. Causes, indications and results in 168 patients. Arch Surg 1979;114:1269-75.

24 Bourassa MG, Campeau L, Lespérance J, Grondin CM. Changes in grafts and coronary arteries after saphenous vein aortocoronary bypass surgery: results at repeat angiography. Circulation 1982;65(suppl II)II:90-7.

25 Chesebro JH, Clements IP, Fuster V, et al. A plateletinhibitor-drug trial in coronary-artery bypass operations. Benefit of peri-operative dipyridamole and aspirin therapy on early postoperative vein graft patency. N Engl J Med 1983;307:73-8.

26 Campeau L, Enjalbert M, Lespérance J, Vaislic C, Grondin CM, Bourassa MG. Atherosclerosis and late closure of aorto coronary saphenous vein grafts: sequential angiographic studies at 2 weeks, 1 year, 5 to 7 years, and 10 to 12 years after surgery. Circulation 1983;68(suppl II)II:1-7.

27 Lawrie GM, Morris GC, Calhoon JH, et al. Clinical results of coronary bypass in 500 patients at least 10 years after operation. Circulation 1982;66(suppl I) I:1-5.

28 Culliford AT, Girdwood RW, Isom W, Krauss KR, Spencer FC. Angina following myocardial revascularisation. Does time of recurrence predict etiology and influence result of operation. $J$ Thorac Cardiovasc Surg 1979;77:889-95.

29 Stiles QR, Cunningham JM. Is re-revascularisation clinically beneficial? Am J Surg 1981;141:656-9.

30 Myers WO, Marshfield WI, Davis K, Foster ED, Maynard C, Kaiser GC. Surgical survival in the Coronary Artery Study (CASS) registry. Ann Thorac Surg 1985;40:245-60.

31 Cosgrove DM, Loop FD, Lytle BW, et al. Determinants of 10-year survival after primary myocardial revascularisation. Ann Surg 1985;202:480-8.

32 Varnauskas E, and the European Coronary Surgery Study Group. Survival, myocardial infarction, and employment status in a prospective randomised study of coronary bypass surgery. Circulation 1985;72(suppl V)V:90-101.

33 Hartzler GO, Rutherford BD, McConahay DR, Johnson WL, Ligon RW, Calkins MM. "Longterm" clinical results of multiple lesion coronary angioplasty in 500 consecutive patients [Abstract]. Circulation 1985;72(suppl III)III:139. 